\title{
Application of Cooperative Learning in College English Classes to Enhance the Students' Learning Initiative
}

\author{
Chunjie Hou', a and Chuanmu Li 2 ,b * \\ ${ }^{1}$ School of Foreign Languages, Jimei University, Xiamen 361021, China \\ ${ }^{2}$ College of Computer Engineering, Jimei University, Xiamen 361021, China \\ ${ }^{a} \mathrm{cjhou@jmu.edu.cn,}{ }^{\mathrm{b}} \mathrm{cm} @ j m u . e d u . c n$
}

Keywords: College English; Cooperative Learning; Traditional Learning; English Learning

Abstract. Nowadays, the concept of cooperative learning is the major trends in education. The instructional methods for improving the quality of classes centered on group learning will be examined through the viewpoint of cooperative learning. First, we will provide a summary of the theory and techniques of cooperative learning and then we will present some thoughts on how to design classes based on cooperative learning. The major findings of this study suggested that cooperative learning helped significantly to enhance the college students' oral communicative competence and their motivation toward learning English. Finally, we will demonstrate that the type of study that can be achieved through class design based on cooperative learning. As a result, the effects of cooperative learning seem salient in enhancing the college students' language learning.

\section{Introduction}

The past decade has seen an explosion of interest among college faculty in the teaching methods variously grouped under the terms 'cooperative learning'. However, even with this interest, there remains much misunderstanding of and mistrust of the pedagogical "movement" behind the words. The majority of all college faculties still teach their classes in the traditional lecture mode. Some of the criticism and hesitation seems to originate in the idea that techniques of cooperative learning are genuine alternatives to, rather than enhancements of, professors' lectures. We provide below a survey of a wide variety of active learning techniques which can be used to supplement rather than replace lectures. We are not advocating complete abandonment of lecturing, as both of us still lecture about half of the class period. The lecture is a very efficient way to present information but use of the lecture as the only mode of instruction presents problems for both the teacher and the students.

As a result, differentiated instruction should be practiced in classes in order to achieve each student. In this case, teachers, when designing lessons, should change the traditional didactic instruction model according to the characteristics of subjects and students' characters and differences, induce students' active learning, and cultivate the transferable skills and applicable knowledge. The application of cooperative learning method could help students understand the learning conditions, create student-centered learning environments, and provide opportunities for students cultivating learning motivation. Accordingly, the effect of cooperative learning model on learning motivation and outcome is discussed in this study in order to achieve the outcome of cooperative learning and allow students being more successful. 


\section{Definition of Cooperative Learning}

Students' learning goals may be structured to promote cooperative, competitive, or individualistic efforts. In every classroom, instructional activities are aimed at accomplishing goals and are conducted under a goal structure. A learning goal is a desired future state of demonstrating competence or mastery in the subject area being studied. The goal structure specifies the ways in which students will interact with each other and the teacher during the instructional session. Each goal structure has its place. In the ideal classroom, all students would learn how to work cooperatively with others, compete for fun and enjoyment, and work autonomously on their own. Within cooperative situations, individuals seek outcomes that are beneficial to themselves and beneficial to all other group members. Cooperative learning is the instructional use of small groups so that students work together to maximize their own and each other's learning.

\section{Basic Elements of Cooperation}

Not all groups are cooperative, placing people in the same room, seating them together, telling them they are a group, does not mean they will cooperate effectively. To be cooperative, to reach the full potential of the group, five essential elements need to be carefully structured into the situation: positive interdependence, individual and group accountability, promotive interaction, appropriate use of social skills, and group processing.

The first and most important element is positive interdependence. Teachers must give a clear task and a group goal so students believe they "sink or swim together." Positive interdependence exists when group members perceive that they are linked with each other in a way that one cannot succeed unless everyone succeeds.

The second essential element of cooperative learning is individual and group accountability. The group must be accountable for achieving its goals. Each member must be accountable for contributing his share of the work. The group has to be clear about its goals and be able to measure (a) its progress in achieving them and (b) the individual efforts of each of its members. Individual accountability exists when the performance of each individual student is assessed and the results are given back to the group and the individual in order to ascertain who needs more assistance, support, and encouragement in completing the assignment.

The third essential component of cooperative learning is promotive interaction, preferably face-to-face. Promotive interaction occurs when members share resources and help, support, encourage, and praise each other's efforts to learn. There are important cognitive activities and interpersonal dynamics that can only occur when students promote each other's learning.

The fourth essential element of cooperative learning is teaching students the required interpersonal and small group skills. In cooperative learning groups students are required to learn academic subject matter and also to teach the interpersonal and small group skills required to function as part of a group. Since cooperation and conflict are inherently related, the procedures and skills for managing conflicts constructively are especially important for the long-term success of learning groups.

The fifth essential component of cooperative learning is group processing. Group processing exists when group members discuss how well they are achieving their goals and maintaining effective working relationships. Continuous improvement of the process of learning results from the careful analysis of how members are working together.

These five elements are essential to all cooperative systems, no matter what their size. When international agreements are made and when international efforts to achieve mutual goals occur, 
these five elements must be carefully implemented and maintained.

\section{Cooperative Learning Approach}

For more complex projects, where many heads are better than one or two, you may want to have students work in groups of three or more. As the term "cooperative learning" suggests, students working in groups will help each other to learn. Generally, it is better to form heterogeneous groups, particularly when the groups will be working together over time or on complex projects; however, some of these techniques work well with spontaneously formed groups. Cooperative groups encourage discussion of problem solving techniques, and avoid the embarrassment of students who have not yet mastered all of the skills required.

Group discussion - Homogeneous group (in the group homogeneous) are often interest groups or friend group, and members of heterogeneous group exist certain complementarities to each other. Groups must be made as far as possible groups members develop reasonably in character, learning achievement, hobby, and many other aspects. It requires the overall level of all groups should be approximately consistent; each group should be the epitome or section of the class. At the same time, each cooperative learning group should be homogeneous in the whole class. Heterogeneous members in the group provide the possibility that they can help each other, and be homogeneous in each group had made the foundation for the equal competition all groups in whole class.

Review - In the traditional class review session the students ask questions and the teacher answers them. Students spend their time copying down answers rather than thinking about the material. In an active review session the teachers possess questions and the students work on them in groups. Then students are asked to show their solutions to the whole group and discuss any differences among solutions proposed.

Time Strategy -Timing cooperative learning affect the learning effect directly. Teachers should choose the valuable content, favorable timing and the appropriate times according to the teaching content, cooperative learning to make students march the cooperative learning strategy. Generally speaking, a simple learning content only need students finish learning independently or carry out the whole class teaching, but more complex and comprehensive learning contents can use the way of cooperation learning

Role Playing - Here students are asked to "act out" a part, they get a better idea of the concepts and theories being discussed. Role-playing exercises can range from the simple to the complex. Complex role playing might take the form of a play.

Debates - Debates provide an efficient structure for class presentations when the subject matter easily divides into opposing views. Students are assigned to debate teams, given a position to defend, and then asked to present arguments in support of their position. The opposing team should be given an opportunity to rebut the arguments and, time permitting, the original presenters asked to respond to the rebuttal. This format is particularly useful in developing argumentation skills.

Teachers' Role -Teachers must participate in the cooperation process and establish the new relationship between teachers and students. Teachers should play a good role in classroom teaching and create a kind of cooperative learning environment. In the process of the organization teachers should organize and manage class teaching activities, try to stimulate the students' participation, and let all students benefit from language practice activity, let the student master the language knowledge emphasis and communication skills through language practice, and make students have a fun experience in participation. 


\section{Results of implementing the cooperative approach}

When introducing cooperative learning method into a class, it is extremely important to require the students to understand the theory and techniques of cooperative learning ahead of time and to provide guidance so that it can be executed. Moreover, the students need to spend a long time talking among them. That is why the teacher needs to make sure that the students acquire the desired concepts and specific skills for group activities in advance, based on the premise of the spirit of cooperation. The once acquired theory and techniques of cooperative learning are not retained indefinitely. For each group activity, the instructor needs to have the students review it in terms of cooperation, get them to appreciate the merits of cooperation, and repeatedly require them to think about the ideals of group activities in order to maintain their effects. In our class, we use cooperative learning method to achieve good teaching results, and gradually extend to other classes. The course has demonstrated that the application of a learner-centered approach combined with a cooperative approach promotes students' communicative competence in both written and oral speech. Delivery with the implementation of the learner-centered approach and cooperative learning though teaching smaller groups, and the cooperative learning in English teaching, some positive results can be reported. The teaching achievements of the course include an increase in students' motivation to learn, and what is more, to use the English language in the learning process and research.

\section{Summary}

Cooperative learning is a theory concerning support for learning in every learning situation but it is not a simple group learning technique. The spirit of cooperation underpins cooperative learning. Students can acquire the spirit of cooperation by repeatedly doing group activities designed with awareness of the basic elements of cooperative learning.

\section{Acknowledgements}

This work was supported by Education and Science Foundation for The Young and middle-aged Scholars of Fujian Province (Grant Number JAS141074) and Natural Science Foundation of Fujian Province of China (Grant Number 2018J01537).

\section{References}

[1] Hmelo-Silver, \& O’Donnell. The international handbook of collaborative learning. New York, NY: Routledge. 78(2013), 227-236.

[2] Johnson, W., Johnson, T., \& Smith, A. Cooperative learning returns to college: What evidence is there that it works? Change, 30(1998), 26-35.

[3] Flynn, A. B. Structure and evaluation of Cooperative work groups. Education Research and Practice, 16(2015), 198-211.

[4] Choi, A., Hand, B., \& Norton-Meier, L. Students' online argumentation about their in-class inquiry investigations. Research in Science Education, 44(2014), 267-287.

[5] Clark, K. R. The effects of the cooperative learning model of instruction on student engagement and performance. Journal of Educators Online, 12(2015), 91-115.

[6] Dass, K., Head, M. L., \& Rushton, G. T. Passion for learning: How project-based learning meets the needs of 21st-century students. Journal of Science Education, 92(2015), 1306-1314. 
[7] Dem, T., \& Ucar, S. The students change with cooperative learning: Students learning from one another. Educational Sciences: Theory and Practice, 15(2015), 267-283. 